\title{
Myeloma-like cast nephropathy in a human immunodeficiency virus infected patient: a case report
}

\author{
Nazrul Hassan Jafry ${ }^{1}$, Muhammad Mubarak ${ }^{2}$, Sabiha Anis ${ }^{3}$, Ejaz Ahmed ${ }^{1}$, Fazal Akhtar ${ }^{1}$ \\ ${ }^{1}$ Department of Nephrology; Sindh Institute of Urology and Transplantation (SIUT), Karachi, Pakistan \\ ${ }^{2}$ Department of Pathology; Sindh Institute of Urology and Transplantation (SIUT), Karachi, Pakistan \\ ${ }^{3}$ Department of Immunology; Sindh Institute of Urology and Transplantation (SIUT), Karachi, Pakistan
}

\section{ABSTRACT}

We report a case of myeloma-like cast nephropathy in a 27-year-old male patient with human immunodeficiency virus (HIV) infection for 2 years. He was on highly active anti-retroviral therapy (HAART) and presented with high grade fever, nausea and vomiting for 2 weeks. On investigations, he was found to have acute kidney injury (AKI). He was started on hemodialysis. Renal biopsy revealed acute tubulointerstitial nephritis with myeloma-like casts in a few tubular lumens. Detailed workup for multiple myeloma was negative. No evidence of monoclonal gammopathy was found. Finally, he was diagnosed as a case of myeloma-like cast nephropathy. With supportive treatment and modification in HAART therapy, his renal functions improved and he became dialysis free in 2 weeks. He was continued on HAART therapy, but he soon discontinued this against medical advice.

Key Words: Myeloma casts, acute tubular injury, HIV, anti-retroviral therapy

\section{BACKGROUND}

With improvement in survival of human immunodeficiency virus (HIV) infected patients due to highly active anti-retroviral therapy (HAART) and prevention of opportunistic infections, other non-infectious manifestations have become more prevalent in these patients. The non-specific or overlapping clinical manifestations of these disorders leads to delay in the diagnosis resulting in complications and poor prognosis ${ }^{1,2}$.

The renal diseases in HIV infected patients did not show a decline in the pre- and post-HAART era. This is due to continuing occurrence of kidney injury due to non-infectious mechanisms and side effects of drugs $5^{3,4}$. Plasma cell dyscrasias are now becoming more evident and an important cause of renal injury in these patients ${ }^{5}$. A timely identification of this abnormality is important for appropriate treatment.

We herein describe a case of an HIV infected young male patient presenting with non-specific clinical features, negative for infectious etiology, polyclonal gammopathy, and severe acute kidney injury (AKI), secondary to myeloma-like cast nephropathy.

\section{CASE REPORT}

A 27-year-old male, resident of Baluchistan and a truck driver by profession, presented with the complaints of high grade fever, nausea and vomiting for two weeks. He also complained of lethargy and malaise since past one month. The fever was not associated with chills or rigors and subsided with paracetamol. There was no history of headache, cough, hemoptysis, shortness of breath or any upper or lower gastrointestinal symptoms at that time. Thereafter, he developed anorexia and weight loss and was admitted to a regional hospital.

There was no history of allergies. Historically, he was positive for HIV infection for two years and was receiving HAART therapy, comprising of Lamivudine, Tenofovir and Efavirenz. He denied any risk factors associated with HIV infection including abnormal behavior, drug abuse or addiction and did not have blood transfusion.

He was married with one male child aged two years. There was no family history of any significant illness such as diabetes, hypertension, cardiac disease or tuberculosis.

Initial laboratory investigations done at regional hospital showed hemoglobin $(\mathrm{Hb})$ of $5.8 \mathrm{~g} / \mathrm{dl}$, blood urea nitrogen (BUN) of $217 \mathrm{mg} /$ $\mathrm{dl}$ and serum creatinine of $14.6 \mathrm{mg} / \mathrm{dl}$. He was referred to our hospital for the management of renal failure.

On general physical examination, he was of average height and weight $(51 \mathrm{~kg})$. He was clinically stable with no abnormal findings on examination of musculoskeletal system, central or peripheral nervous system, respiratory system, cardiovascular system, abdomen, genitourinary system and eyes. There was no numbness / paresthesia or any behavioral or personality changes. He was afebrile with stable vitals (blood pressure of $120 / 80 \mathrm{~mm} / \mathrm{Hg}$, pulse, 88 beats/minute and 
respiratory rate, 16 breaths/minute). However, he was severely anemic with $\mathrm{Hb}$ of $5.7 \mathrm{~g} / \mathrm{dl}$. Peripheral blood film showed normochromia and anisocytosis. White blood cell (WBC) count was $11,700 / \mathrm{ml}$, platelets, $260,000 / \mathrm{ml}$ and erythrocyte sedimentation rate (ESR) of $140 \mathrm{~mm}$ at $1^{\text {st }}$ hour. C-reactive protein (CRP) was $2.4 \mathrm{mg} / \mathrm{dl}$. Other laboratory investigations at our center showed serum creatinine of $14.3 \mathrm{mg} / \mathrm{dl}$, BUN of $739 \mathrm{mg} / \mathrm{dl}$, serum sodium, $134 \mathrm{mEq} / \mathrm{L}$, serum potassium, 3.5 $\mathrm{mEq} / \mathrm{L}$, serum bicarbonate, $3 \mathrm{mEq} / \mathrm{L}$ and serum chloride, $103 \mathrm{mEq} / \mathrm{L}$. Serum total proteins were $9.6 \mathrm{~g} / \mathrm{dl}$, serum albumin, $3.4 \mathrm{~g} / \mathrm{dl}$, and serum globulins, $6.2 \mathrm{~g} / \mathrm{dl}$, with altered albumin to globulin (A/G) ratio of 0.55 .

His immunological workup indicated that he had very low count of CD4+ T cells ( 48 cells $/ \mathrm{ml}$ ) and HIV RNA viral load of $4 \times 10^{4}$ copies/ $\mathrm{ml}$. He reacted negative for hepatitis $B$ surface antigen ( $\mathrm{HBsAg}$ ), and hepatitis $C$ virus (HCV) antibodies. Antinuclear antibody (ANA), antidouble stranded DNA (dsDNA), rheumatoid factor (RA) factor and cryoglobulins were negative. Serum IgG was $30.3 \mathrm{mg} / \mathrm{dl}$, IgA, $8.6 \mathrm{mg} /$ dl, IgM, $1.2 \mathrm{mg} / \mathrm{dl}, \mathrm{C} 3,1.34 \mathrm{mg} / \mathrm{dl}$ and C4, $0.31 \mathrm{mg} / \mathrm{dl}$. Kappa light chains were $2850 \mathrm{mg} / \mathrm{dl}$ and lambda chains, $1570 \mathrm{mg} / \mathrm{dl}$; both were markedly raised.

Urine detailed report showed proteinuria of +1 with occasional red blood cells (RBCs). Ultrasound abdomen showed no abnormality with right kidney measuring $9.8 \mathrm{~cm}$ and left kidney, $10.5 \mathrm{~cm}$. Echocardiogram was normal with ejection fraction of $63 \%$. Vegetations were not present.

Because of his deranged renal function, Tenofovir was switched to Abacavir. Angio-access was gained through right internal jugular double lumen catheter and hemodialysis was started along with two pints of packed cell transfusion. Thereafter, patient underwent maintenance hemodialysis after every two days.

\section{Figure 1}

Renal biopsy showing hard cast in one tubule. The glomerulus is unremarkable. There is interstitial inflammation in the background. (HE, $\times 400)$

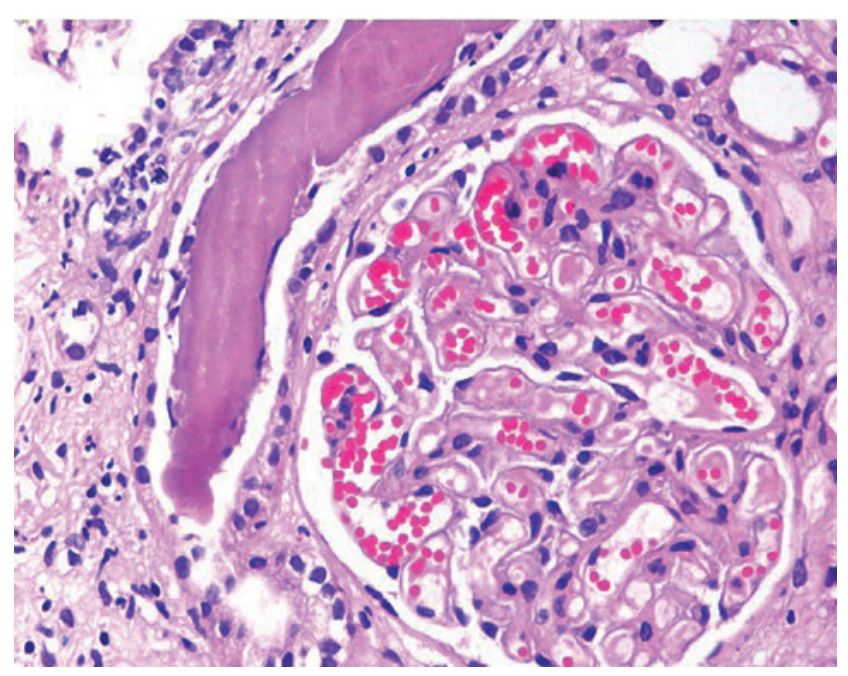

Because of mild proteinuria, abnormal renal functions and normal sized kidneys, renal biopsy was done which showed lesions of tubulointerstitial nephritis with many distal tubules and collecting ducts containing intraluminal casts resembling myeloma casts as shown in Figure 1. Immunohistochemical staining for kappa and lambda light chains co-expression of both light chains. No crystals were found. The glomeruli were unremarkable. As the myeloma casts are typically found in patients with monoclonal gammopathy, additional relevant tests were done. Bone marrow trephine biopsy showed adequate cellularity with a few scattered mature plasma cells. Chest X-ray (Figure 2) and skull radiograph (Figure 3) did not show lytic lesions or any other abnormality.

\section{Figure 2}

Chest X-ray PA view demonstrates normal lung fields; no active or chronic lung lesions are seen. Both hilar areas appear normal. No lymphadenopathy. Cardiac size appears normal. Visualized bones also appear normal. No lytic, erosive or destructive lesions are seen.

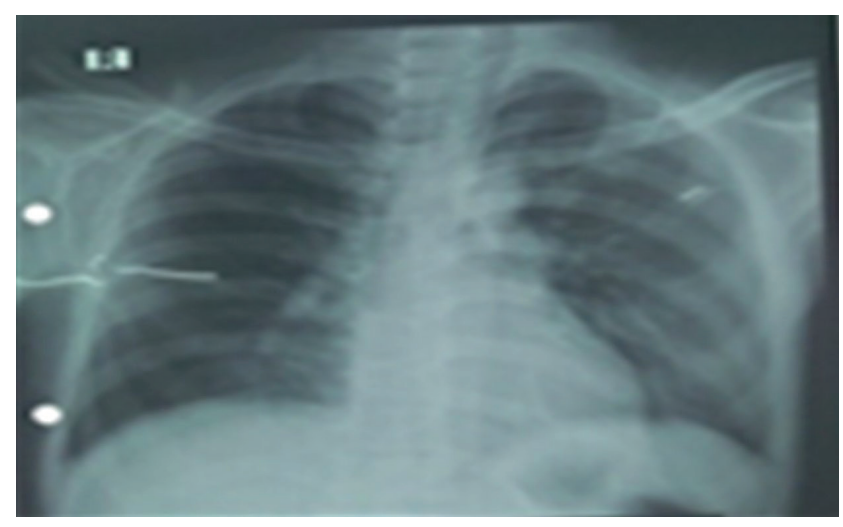

\section{Figure 3}

Skull radiogram anteroposterior and lateral views showing normal skull vault and diploic space. Pituitary fossa also appears normal. No lytic or destructive lesion is seen.

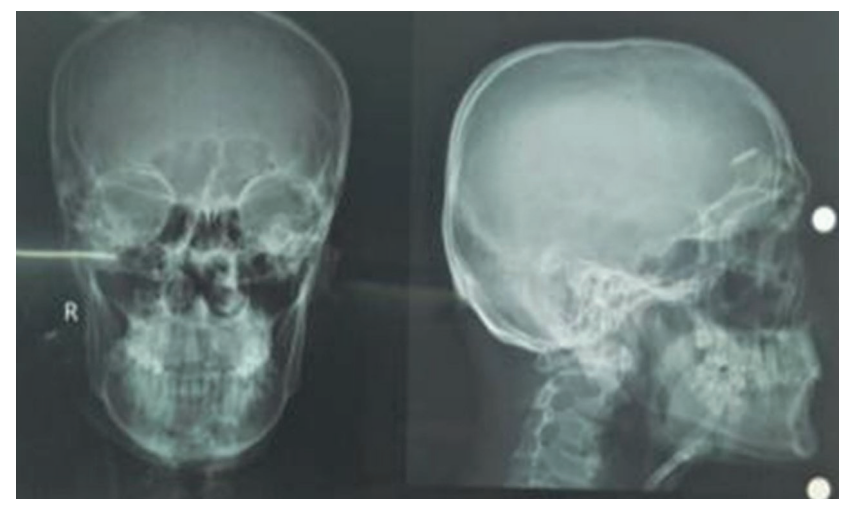




\section{Figure 4}

Images of serum (A) and urine (B) immunofixation electrophoresis. There is a high density, heterogeneous band on serum protein electrophoresis with corresponding polyclonal increase in heavy and light chains of all immunoglobulins. Urine protein electrophoresis and immunofixation is showing considerable proteinuria with leakage of $\lg G$ and light chains.

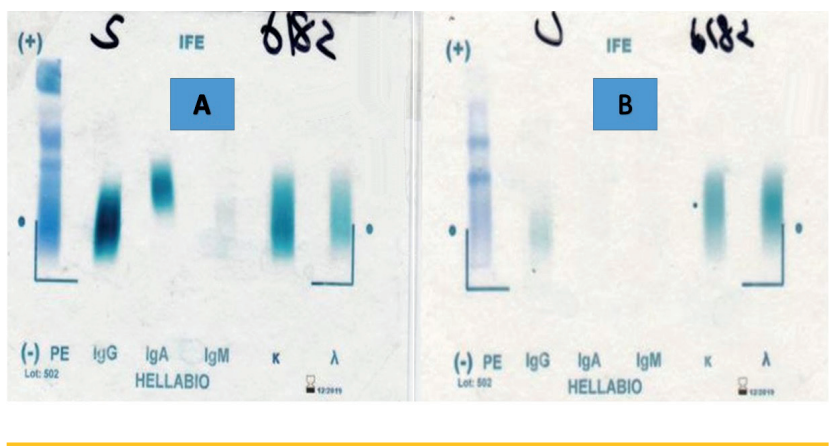

Serum and urinary protein electrophoresis and immunofixation were done which showed polyclonal gammopathy (Figure 4), as evident by raised immunoglobulins IgG and IgA, noted above. Hence, a final diagnosis of acute HIV-associated myeloma-like cast nephropathy was made. His dialysis was continued, his urine output started to increase and he became dialysis free in 2 weeks. He was advised to continue HAART therapy and was advised regular follow-up in adult nephrology clinic.

\section{DISCUSSION}

After the advent of HAART therapy in 1997, infectious complications have reduced in HIV infected patients but at the expense of emergence of non-infectious complications ${ }^{1-3}$. Acute and chronic kidney injury remain a common complication in HIV infected patients both in pre- and post-HAART era with an incidence of up to $20 \%$ in these patients. Broadly, two patterns of HIV kidney disease have emerged: HIV associated nephropathy (HIVAN) and HIV-immune complex kidney disease (HIVICK). HIVAN is thought to be caused by direct infection of the kidney parenchyma by HIV-1 infection. HIVAN classically presents as a collapsing glomerulopathy, and is the most common renal complication amongst patients with HIV-1 infection. HIVICK is an immune complex-mediated glomerulonephritis, which is characterized by immune complex deposition in the glomeruli that include complement, HIV-1 antigens and reactive antibodies. In addition, nephrotoxic antibiotics and even HAART therapy also represent an important cause of nephrotoxicity ${ }^{3}$.

Besides immunodeficiency, there is a loss of tolerance and subsequently immune dysregulation in HIV-1 infected patients, which can be a major cause of renal injury. Due to abolition of T cell check on $B$ cell function, aberrant proliferation of these cells occurs giving rise to a spectrum of gammopathies from polyclonal to monoclonal ${ }^{6}$. Konstantinopoulos et al $^{6}$ studied the prevalence and nature of immunoglobulin abnormalities in HIV-1 infected patients in the era of HAART and found polyclonal gammopathy in $1.9 \%$ of HIV infected patients while low concentration ( $<5 \%$ of total proteins) monoclonal band in $4 \%$ patients on serum protein electrophoresis and immunofixation.

Bonnet $\mathrm{F}$ et al, in his study of 97 HIV infected patients reported evidence of immune dysregulation with or without the presence of HCV infection. They found cryoglobulinemia in $17 \%$ and prevalence of other autoantibodies ranging from $17 \%$ to $51 \%$ in HIV positive and HCV non-infected patients ${ }^{7}$. However they also found that cryoglobulins were found in lesser number in patients receiving HAART with lower levels of concentration compared to HCV infected patients ${ }^{7}$. Cryoglobulins are abnormal immunoglobulins found in many viral infections and autoimmune diseases and have a strong association with HCV infection. The three types of cryoglobulins can be classified by serum protein immunofixation electrophoresis at $37^{\circ} \mathrm{C}$. Arising as a result of aberrant polyclonal activation of $B$ cells, it may lead to oligoclonal and then monoclonal $B$ cell proliferation resulting in nonHodgkin's lymphoma ${ }^{8}$. Therefore, the presence of polyclonal gammopathy in HIV infected patients should be taken seriously with further investigations to ensure an accurate diagnosis and timely management.

Histopathologically, plasma cell dyscrasias affecting kidneys shows heterogeneous morphological features as illustrated by Herrera et $\mathrm{al}^{9}$. These include cast nephropathy, AL amyloid and others. A polyclonal increase in immunoglobulin levels is seen in patients with chronic infections or in autoimmune or connective tissue disorders due to persistent antigenic challenge $^{10}$. In HIV infected patients, hypergammaglobulinemia or polyclonal gammopathy reflects severity of HIV disease or AIDS. Serpa et al ${ }^{11}$ have shown in their study that a decrease in hypergammaglobulinemia can be used as a surrogate marker for effective HAART treatment. This is in contrast to the situation in multiple myeloma patients, where successful therapy is indicated by an increase in polyclonal immunoglobulins, a reflection of the recovery of the normal immune system ${ }^{12}$. Therefore, persistence of increased immunoglobulin levels with formation of myeloma-like casts in our patient can be an indication of either treatment failure or non-compliance. Early detection of persistent polyclonal increase in immunoglobulins may help in reducing these complications caused by plasma cell dyscrasias.

Our patient presented with acute renal failure apparently due to nephrotoxicity by excessively filtered light chains in urine. This was also reflected by the renal biopsy findings which revealed myelomalike casts in distal tubules and collecting ducts. Classically, these casts usually indicate the presence of abnormal or altered immunoglobulins precipitated in the renal tubules and mostly found in multiple myeloma ${ }^{13}$. However, there are case reports of HIV-1 infected patients with myeloma-like cast nephropathy with laboratory evidence of polyclonal gammopathy ${ }^{14,15}$. This case report and the previous ones highlight the importance of investigating HIV positive patients thoroughly for polyclonal increase in immunoglobulins ${ }^{16}$.

To conclude, it is important to keep in mind this new pattern of HIV-related nephropathy. Our case report emphasizes the need to keep in mind other causes of presence of myeloma-like casts besides myeloma in these patients for an appropriate management

Disclosure of potential conflicts of interest: none declared. 


\section{References}

1. Cobucci RN, Lima PH, de Souza PC, Costa VV, Cornetta Mda C, Fernandes JV, et al. Assessing the impact of HAART on the incidence of defining and non-defining AIDS cancers among patients with HIV/AIDS: a systematic review. J Infect Public Health. 2015 Jan-Feb;8(1):1-10.

2. Quinn TC. HIV epidemiology and the effects of antiviral therapy on long-term consequences. AIDS 2008 Sep;22(3):S7-12

3. Kalim S, Szczech LA, Wyatt CM. Acute kidney injury in HIV-infected patients. Semin Nephrol. 2008 Nov;28(6):556-62.

4. Izzedine H, Baumelou A, Deray G. Acute renal failure in HIV patients. Nephrol Dial Transplant. 2007 Oct;22(10):2757-62.

5. Coker WJ, Jeter A, Schade H, Kang Y. Plasma cell disorders in HIV-infected patients: epidemiology and molecular mechanisms. Biomark Res. 2013 Feb; 4(1):8.

6. Konstantinopoulos PA, Dezube BJ, Pantanowitz L, Horowitz GL, Beckwith BA: Protein electrophoresis and immunoglobulin analysis in HIV-infected patients. Am J Clin Pathol. 2007;128(4):596-603.

7. Bonnet F, Pineau JJ, Taupin JL, Feyler A, Bonarek M, de Witte S, et al. Prevalence of cryoglobulinemia and serological markers of autoimmunity in human immunodeficiency virus infected individuals: a cross-sectional study of 97 patients. J Rheumatol. 2003:30(9):2005-10.

8. Caviglia GP, Sciacca C, Abate ML, Olivero A, Rosso C, Touscoz GA, et al. Chronic hepatitis C virus infection and lymphoproliferative disorders: mixed cryoglobulinemia syndrome, monoclonal gammopathy of undetermined significance, and B-cell non-Hodgkin lymphoma. J Gastroenterol Hepatol. 2015;30(4):742-47.

9. Herrera GA, Joseph L, Gu X, Hough A, Barlogie B. Renal pathologic spectrum in an autopsy series of patients with plasma cell dyscrasia. Arch Pathol Lab Med. 2004;128(8):875-79.

10. O'Connell TX, Horita TJ, Kasravi B. Understanding and interpreting serum protein electrophoresis. Am Fam Physician 2005;71(1):105-12.

11. Serpa J, Haque D, Valayam J, Breaux K, Rodriguez-Barradas MC. Effect of combination antiretroviral treatment on total protein and calculated globulin levels among HIV-infected patients. Int J Infect Dis. 2004;14(3):e41-44.
12. Zamarin D, Devlin S, Arcila M, Giralt SA, Landau H, Lesokhin A, et al. Reactive polyclonal gammopathy associated with polyclonal plasmacytosis is common in patients with multiple myeloma receiving prolonged lenalidomide therapy: a retrospective study of 104 patients. Blood. 2012;120(21):4033.

13. Stringer S, Basnayake K, Hutchison C, Cockwell P. Recent advances in the pathogenesis and management of cast nephropathy (myeloma kidney). Bone Marrow Res.2011:493697.

14. Khurram MS, Alrajjal A, Ibrar W, Edens J, Sheikh U, Hamza A, et al. Cisplatin-induced nephrotoxicity and HIV associated nephropathy: mimickers of myeloma-like cast nephropathy. Case Rep Nephrol. 2017;2017:6258430.

15. Sheikh U, Anderson I, Socec C, Qu H: Myeloma-like cast nephropathy in Human Immunodeficiency Virus (HIV)-infected patients: recognition of a new pattern in two cases. American Journal of Clinical Pathology. 2013;140(1):A186

16. Lucas GM, Ross MJ, Stock PG, Shlipak MG, Wyatt CM, Gupta SK, et al. Clinical practice guideline for the management of chronic kidney disease in patients infected with HIV: 2014 update by the HIV Medicine Association of the Infectious Diseases Society of America. Clin Infect Dis. 2014 Nov;59(9):e96-138.

\section{Correspondence to:}

Nazrul Hassan Jafry, MD

Department of Nephrology,

Sindh Institute of Urology and Transplantation (SIUT),

Karachi-74200, Pakistan,

Email address: dr_nazar_jafferi@yahoo.com 